\title{
(10) \\ Fabrication of Co-W Alloy/Multiwalled Carbon Nanotube Composite Films by Electrodeposition for Improved Frictional Properties
}

\author{
Susumu Arai*,z and Kazuaki Miyagawa \\ Department of Chemistry and Material Engineering, Faculty of Engineering, Shinshu University, \\ Nagano 380-8553, Japan
}

Co-W alloy/multiwalled carbon nanotube (MWCNT) composite films were fabricated using an electrodeposition technique and their microstructures were characterized. A citrate bath was used as the Co-W alloy/MWCNT composite plating bath. A compact Co-W alloy/MWCNT composite film having uniform distribution of MWCNTs without cracks was electrodeposited by adjusting the $\mathrm{pH}$ and current density. Frictional properties of the $\mathrm{Co}-\mathrm{W}$ alloy/MWCNT composite film were evaluated using a ball-on-disk method at room temperature as well as at elevated temperatures $\left(\sim 300^{\circ} \mathrm{C}\right)$ without any lubricant. The coefficient of friction of the Co-W alloy/MWCNT composite film was clearly lower than that of a Co-W alloy film with the same tungsten content at room temperature. The coefficient of friction of the Co-W alloy/MWCNT composite film increased with increasing temperature. However, the coefficient of friction of the Co-W alloy/MWCNT composite film was lower than that of a Co-W alloy film with the same tungsten content at elevated temperatures.

(C) 2013 The Electrochemical Society. [DOI: 10.1149/2.036311jss] All rights reserved.

Manuscript submitted August 26, 2013; revised manuscript received September 20, 2013. Published September 25, 2013.

Due to their high hardness, wear resistance, ${ }^{1}$ and high corrosion resistance, ${ }^{2,3} \mathrm{Co}-\mathrm{W}$ alloy plating films are expected to be a substitute for chromium plating films, which are formed in an environmentally hazardous process using hexavalent chromium. ${ }^{1-11}$ The formation of Co-W alloy films by electrodeposition was first reported by Holz, ${ }^{12}$ and their deposition behaviors, ${ }^{13,14}$ mechanism, ${ }^{15}$ microstructures ${ }^{16-18}$ and properties ${ }^{3-12,20-24}$ have been vigorously studied. The formation of Co-W alloy based composite films, such as $\mathrm{Co}-\mathrm{W}$ alloy/CaF ${ }_{2}{ }^{25}$ and $\mathrm{Co}-\mathrm{W}$ alloy/ $\mathrm{Al}_{2} \mathrm{O}_{3}{ }^{26}$ composite films, has also been investigated to improve the properties of the $\mathrm{Co}-\mathrm{W}$ alloy films. Periene et al. reported $\mathrm{Co}-\mathrm{W}$ alloy based composite films with various inorganic powders containing $\mathrm{ZrO}_{2}, \mathrm{Cr}_{2} \mathrm{O}_{3}, \mathrm{SiC}$, and $\mathrm{TiB}_{2} .{ }^{27}$ The electrodeposition of $\mathrm{Co}-\mathrm{W}$ alloy films has been investigated using various plating baths including acidic baths, ${ }^{14,28}$ citrate baths, ${ }^{1,7,8,12,15,16,19,29-31}$ ammoniac baths, ${ }^{32}$ gluconate baths, ${ }^{5,11}$ and citrate-ammonia baths. ${ }^{6}$

Due to their superior mechanical properties, very high thermal conductivity, and excellent solid lubricity, carbon nanotubes $(\mathrm{CNT})^{33,34}$ are expected to be used as fillers for functional composite materials. Consequently, the formation of metal/CNT composites has been studied by various methods including plating techniques for various applications. Fabrication of metal/CNT composite films for use in tribological applications has also been extensively researched using electrodeposition ${ }^{35-37}$ and electroless deposition. ${ }^{38-40}$ These studies demonstrated that metal/CNT composite films show lower apparent coefficients of friction compared to simple metal films without CNTs at room temperature.

Co-W alloy/CNT composite films are thus a potential candidate to replace chromium plating films. However, there have been no reports on Co-W alloy/CNT composite films so far. In this study, Co-W alloy/CNT composite films were fabricated using an electrodeposition technique. The tribological properties of the Co-W alloy/MWCNT composite film were evaluated at room temperature as well as at high temperatures.

\section{Experimental}

The CNTs used in the present study are commercially available vapor-grown MWCNTs (Showa Denko Co. Ltd.), formed via catalyst-assisted $\mathrm{CVD}^{41}$ and heat treated at $2800^{\circ} \mathrm{C}$ in an argon atmosphere for $30 \mathrm{~min}$. The MWCNTs were typically $100-150 \mathrm{~nm}$ in diameter and $10-15 \mu \mathrm{m}$ in length. A citrate (or citrateammonia) bath $\left(0.09 \mathrm{~mol} \mathrm{dm}^{-3} \mathrm{CoSO}_{4} \cdot 7 \mathrm{H}_{2} \mathrm{O}+0.29 \mathrm{~mol} \mathrm{dm}^{-3}\right.$

${ }^{*}$ Electrochemical Society Active Member.

${ }^{\mathrm{z} E-m a i l: ~ a r a i s u n @ s h i n s h u-u . a c . j p ~}$
$\mathrm{Na}_{2} \mathrm{WO}_{4} \cdot 2 \mathrm{H}_{2} \mathrm{O}+0.25 \mathrm{~mol} \mathrm{dm}{ }^{-3}\left(\mathrm{NH}_{4}\right)_{2} \mathrm{HC}_{6} \mathrm{H}_{5} \mathrm{O}_{7}+0.25 \mathrm{~mol} \mathrm{dm}^{-3}$ $\mathrm{Na}_{3} \mathrm{C}_{6} \mathrm{H}_{5} \mathrm{O}_{7} \cdot 2 \mathrm{H}_{2} \mathrm{O}$ ) was used as the base alloy bath. ${ }^{42}$ The MWCNTs did not disperse uniformly in the base bath; therefore, a homogeneous dispersion of MWCNTs was achieved by the addition of a polyacrylic acid (mean molecular weight 5000; PA5000) dispersant ${ }^{43-45}$ to the base bath with stirring.

The composition of the Co-W alloy/MWCNT composite plating bath used in the present study was $0.09 \mathrm{~mol} \mathrm{dm}^{-3} \mathrm{CoSO}_{4} \cdot 7 \mathrm{H}_{2} \mathrm{O}$ $+0.29 \mathrm{~mol} \mathrm{dm}^{-3} \mathrm{Na}_{2} \mathrm{WO}_{4} \cdot 2 \mathrm{H}_{2} \mathrm{O}+0.25 \mathrm{~mol} \mathrm{dm}-3\left(\mathrm{NH}_{4}\right)_{2} \mathrm{HC}_{6} \mathrm{H}_{5} \mathrm{O}_{7}$ $+0.25 \mathrm{~mol} \mathrm{dm}^{-3} \mathrm{Na}_{3} \mathrm{C}_{6} \mathrm{H}_{5} \mathrm{O}_{7} \cdot 2 \mathrm{H}_{2} \mathrm{O}+2 \times 10^{-5} \mathrm{~mol} \mathrm{dm}^{-3} \mathrm{PA} 5000$ $+1.5 \mathrm{~g} \mathrm{dm}^{-3}$ MWCNTs. Bath $\mathrm{pH}$ was varied from 4.0 to 5.0. A commercially available electrolytic cell (Microcell Model I, YamamotoMs Co. Ltd) with internal dimensions of $65 \times 65 \times 95 \mathrm{~mm}^{3}$ was employed for the electrodeposition. The volume of the plating bath was $300 \mathrm{~cm}^{3}$. A pure copper plate $(\mathrm{C} 1020)$ with an exposed surface area of $10 \mathrm{~cm}^{2}\left(3 \times 3.33 \mathrm{~cm}^{2}\right)$ was used as the substrate. A platinumplated titanium plate was used as the anode. Electrodeposition was performed under galvanostatic conditions at current densities of 5 and $10 \mathrm{~A} \mathrm{dm}^{-2}$ with aeration. The bath temperature was $60^{\circ} \mathrm{C}$.

Microstructures of the films were examined using a field-emission scanning electron microscope (FE-SEM; JEOL JSM-7000F). The tungsten content (at \%) of the films was measured using electron probe X-ray microanalysis (EPMA, Shimadzu Seisakusho EPMA-1610). The tungsten content of the $\mathrm{Co}-\mathrm{W}$ alloy/MWCNT composite films was calculated in at\% for the Co-W alloy matrices. Exclusive sample preparation equipment (Cross-section polisher; JEOL SM-09010) was used to prepare cross-sectional samples for FE-SEM observations and EPMA elementary mapping analysis. The MWCNT content (mass\%) in the composite films was determined by direct weighing. For the weight measurement, thick Co-W alloy/MWCNT composite films (over $2 \mathrm{~g}$ ) were electrodeposited on a stainless steel (SUS304) substrate. After exfoliation of the composite films from the stainless steel substrate, the Co-W alloy matrix of the films was dissolved in aqua regia. The MWCNTs in the aqua regia solution were then filtered, dried and weighed.

The phase structures of the films were examined by X-ray diffraction (XRD, Shimadzu Seisakusho XRD-6000). The hardness of the films was measured using a micro-Vickers hardness tester (Shimadzu Seisakusho DUH-201). The frictional properties of the films were measured using a ball-on-disk type friction test machine (High Temperature Tribometer, CSM Instruments THT1000). For the frictional tests, the films were electrodeposited on a steel substrate (SPCC). An alumina ball (6 mm diameter, HV: 1500) was used as the countersurface. Tests were conducted without using lubricants and under ambient conditions ranging from room temperature to $300^{\circ} \mathrm{C}$. The coefficient of friction was measured continuously using a load cell 

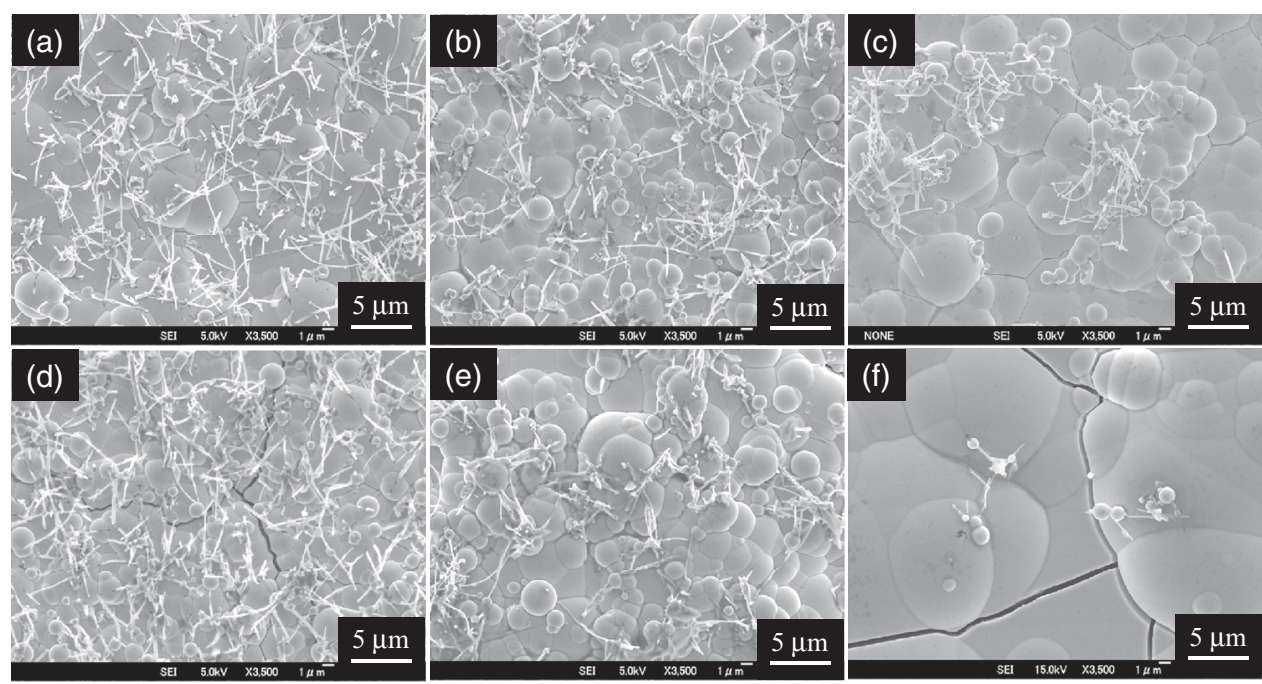

Figure 1. Surface SEM images of Co-W alloy/MWCNT composite films electrodeposited under various conditions: (a) current density: $5 \mathrm{~A} \mathrm{dm}^{-2}$, $\mathrm{pH}: 4.0$, (b) current density: $5 \mathrm{~A} \mathrm{dm}^{-2}, \mathrm{pH}: 4.5$, (c) current density: $5 \mathrm{~A} \mathrm{dm}^{-2}, \mathrm{pH}: 5.0$, (d) current density: $10 \mathrm{~A} \mathrm{dm}^{-2}, \mathrm{pH}: 4.0$, (e) current density: $10 \mathrm{~A} \mathrm{dm}{ }^{-2}$, pH: 4.5 , and (f) current density: $10 \mathrm{~A} \mathrm{dm}^{-2}$, pH: 5.0. Corresponding tungsten contents are (a) 17, (b) 19, (c) 20, (d) 21, (e) 24 and (f) 26 at $\%$.

during the tests. The wear volume was calculated from the crosssectional areas of wear scars, which were measured using a roughness meter (Taylor Hobson Surtronic 25). The wear rate was calculated using the wear volume, the test load, and the sliding distance.

\section{Results and Discussion}

For fabricating the Co-W alloy/MWCNT composite films, not only tungsten content but also uniform MWCNT incorporation is a very important aspect. Figure 1 shows SEM images of the surfaces of the Co-W alloy/MWCNT composite films electrodeposited under various conditions. In this study, Co-W alloy/MWCNT composite films with 17-26 at\% tungsten content were formed; the tungsten content tended to increase with increasing $\mathrm{pH}$ values and current densities. The maximum tungsten content of 26 at $\%$ was obtained at $\mathrm{pH}=5.0$ and $10 \mathrm{~A} \mathrm{dm}^{-2}$ (Fig. 1f).

The uniformity and quantity of MWCNT incorporation also changed depending on the electrodeposition conditions used. At $5 \mathrm{~A} \mathrm{dm}^{-2}$, a significant amount of MWCNTs with uniform distribution were incorporated in the film at $\mathrm{pH}=4.0$ (Fig. 1a). The uniformity and quantity of the MWCNTs tended to decrease with increasing $\mathrm{pH}(\mathrm{pH}$ $=4.5$, Fig. $1 \mathrm{~b}$ ) and the MWCNTs were incorporated as aggregates, i.e., as secondary particles. The quantity of MWCNTs decreased further at $\mathrm{pH}=5.0$ (Fig. 1c). At $10 \mathrm{~A} \mathrm{dm}^{-2}$, a similar tendency was found for the uniformity and quantity of the MWCNTs (Figs. 1d 1f). These results suggest that the dispersibility of the MWCNTs in the plating baths was changed by changing the bath $\mathrm{pH}$, and the dispersibility of the MWCNTs decreased with increasing $\mathrm{pH}$, resulting in incorporation of aggregated MWCNTs or lesser incorporation of MWCNTs in the film. Furthermore, cracks were found in the composite films electrodeposited at $10 \mathrm{~A} \mathrm{dm}^{-2}$ (Figs. 1d and 1f). From these results, the Co-W alloy/MWCNT composite film electrodeposited at $\mathrm{pH}=4.0$ and $5 \mathrm{~A} \mathrm{dm}^{-2}$ (Fig. 1a, Co-17 at\% W alloy/MWCNT composite film) was selected as the representative composite film and the characterizations were carried out for this sample.

Figure 2 shows a cross-sectional SEM image of the Co-W alloy/MWCNT composite film shown in Fig. 1a. There are no cracks or voids in the composite film and the MWCNTs are distributed uniformly across the composite film. Figure 3 shows the results of EPMA elementary mapping analysis of the cross section of the composite film. The distribution of carbon indicates the distribution of the MWCNTs (Fig. 3b). Cobalt and tungsten distribute homogeneously across the composite film (Figs. 3c and 3d). From Figs. 2 and 3,

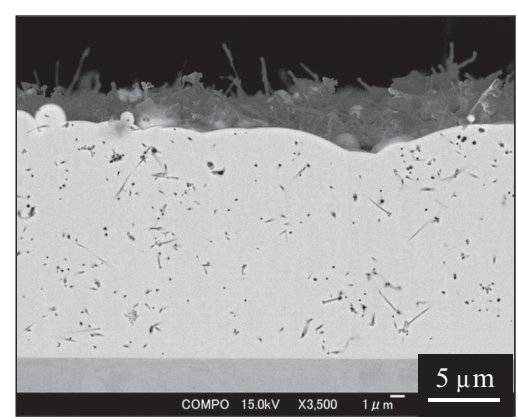

Figure 2. Cross-sectional SEM image of Co-W alloy/MWCNT composite film. Tungsten content: 17 at\%.
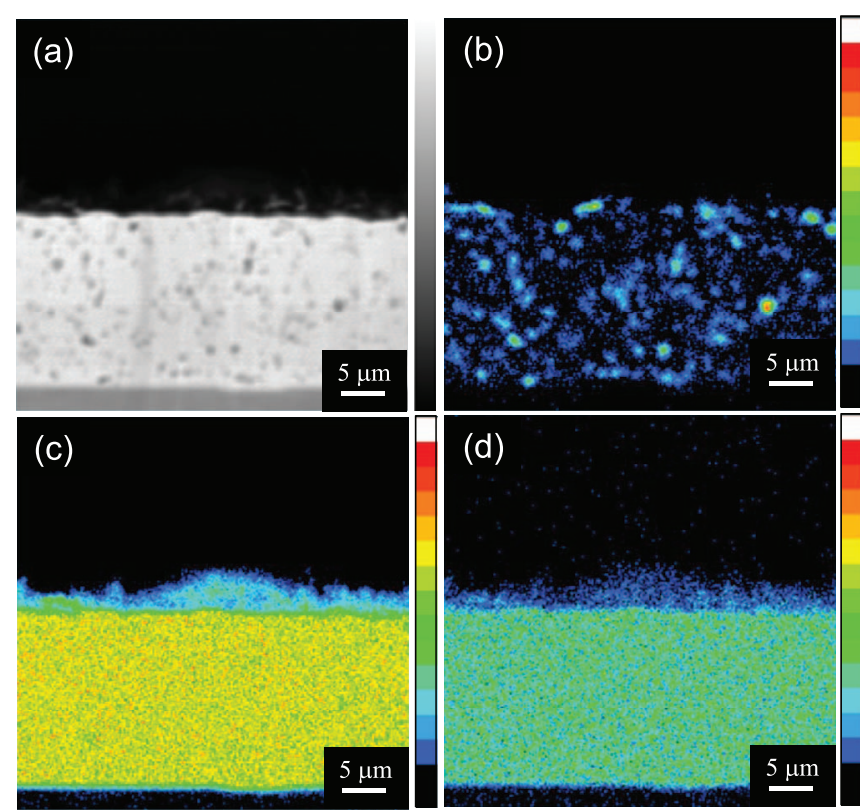

(d)

Figure 3. EPMA mapping analysis of a cross-section of the Co-W alloy/MWCNT composite film: (a) backscattered electron image, (b) distribution of carbon, (c) distribution of cobalt and (d) distribution of tungsten. Tungsten content: 17 at $\%$. 


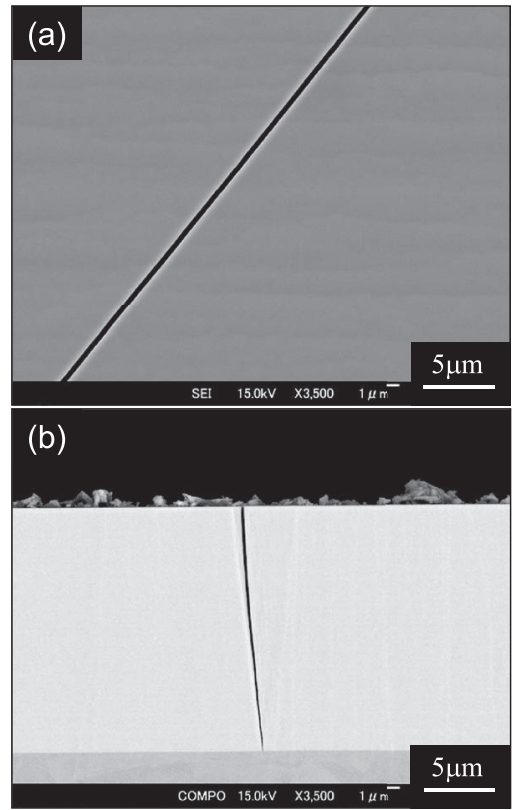

Figure 4. Surface and cross-sectional SEM image of the Co-W alloy film. Tungsten content: 17 at $\%$.

the Co-W alloy/MWCNT composite film is seen to have a compact structure with uniform MWCNT distribution across the homogeneous Co-W alloy matrix.

In order to clarify the effects of the MWCNTs on the properties of the composite film, a Co-W alloy film was electrodeposited from the base alloy bath using the same electrodeposition conditions as used for the Co-W alloy/MWCNT composite film (pH: 4, current density: $5 \mathrm{~A} \mathrm{dm}^{-2}$ ). The tungsten content of the alloy film was $17 \mathrm{at} \%$, which was the same as in the Co-W alloy/MWCNT composite film. Figure 4 shows surface and cross-sectional SEM images of the Co-W alloy film. The Co-W alloy film had a very smooth surface morphology and compact structure with some cracks. The Co-W alloy film also proved to have homogeneous composition across the alloy film, as seen from the results of EPMA elementary mapping analysis. Figure 5 shows the XRD patterns of the $\mathrm{Co}-\mathrm{W}$ alloy and the $\mathrm{Co}-\mathrm{W}$ alloy/MWCNT composite films. A broad peak assigned to the hexagonal cobalt (101) plane is seen in each diffraction pattern at around $45^{\circ}$. Therefore, the Co-W alloy film and the matrix of the Co-W alloy/MWCNT composite film have the same amorphous or nano-crystalline structure. No clear

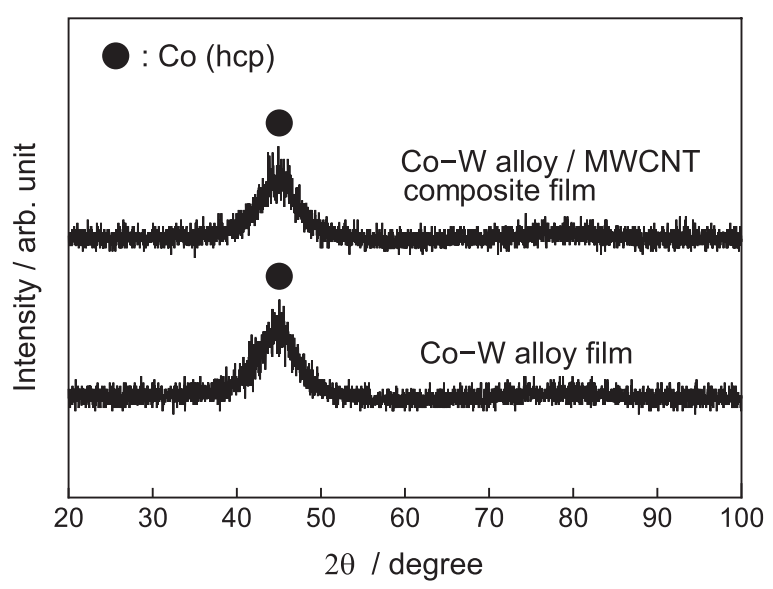

Figure 5. XRD patterns of the Co-W alloy/MWCNT composite film and the Co-W alloy film. Tungsten content for both: 17 at\%.

\begin{tabular}{lcc}
\hline $\begin{array}{l}\text { Table I. Specifications of Co-W } \\
\text { MWCNT composite film. }\end{array}$ & $\begin{array}{c}\text { Co-W } \\
\text { alloy/MWCNT } \\
\text { composite film }\end{array}$ \\
Specification & Co-W alloy film & 17 \\
\hline Tungsten content (at\%) & 17 & 0.57 \\
MWCNT content (mass\%) & 0 & 447 \\
Hardness (HV) & 408 &
\end{tabular}

diffraction peak of the MWCNTs was found in the XRD pattern for the Co-W alloy/MWCNT composite film. This may be because the quantity of MWCNTs in the composite film was not sufficient for XRD detection.

Table I shows the specifications of the Co-W alloy film and the Co$\mathrm{W}$ alloy/MWCNT composite film. The tungsten content in both films was 17 at $\%$ as described above. The MWCNT content in the composite film was 0.57 mass $\%$. The hardness of the $\mathrm{Co}-\mathrm{W}$ alloy/MWCNT composite film was $447 \mathrm{HV}$, which is a little higher than that of the Co-W alloy film (408 HV). This may be due to dispersion-hardening due to the presence of the MWCNTs.

Figure 6 shows the variation of the coefficient of friction for the Co-W alloy film and the Co-W alloy/MWCNT composite film. The measurements were carried out under mild conditions (temperature: room temperature, test load: $2 \mathrm{~N}$, rotation speed: $1.0 \mathrm{~cm} \mathrm{~s}^{-1}$, sliding distance: $12 \mathrm{~m}$ ). The coefficient of friction for the Co-W alloy film increased gradually from the initial value of 0.22 to the final value of 0.52 . In contrast, the coefficient of friction for the Co-W alloy/MWCNT composite film decreased from the initial value of 0.17 to 0.1 at the first stage and the value of 0.1 was maintained until the final stage $(12 \mathrm{~m})$. Thus, the Co-W alloy/MWCNT composite film clearly showed a lower coefficient of friction compared to the $\mathrm{Co}-\mathrm{W}$ alloy film.

SEM images of the wear scars on the films after the wear tests are shown in Fig. 7. A clear, continuous scar is evident on the surface of the Co-W alloy film (Fig. 7a). In contrast, the wear scar on the Co-W alloy/MWCNT composite film is discontinuous (Fig. 7b). Enlarged SEM images of the scars in Fig. 7a and 7b are shown in Fig. 7c and 7d, respectively. Compared to the scar on the Co-W alloy film (Fig. 7c), the scar on the Co-W alloy/MWCNT composite film is limited to just a partial area and most of the area remained unchanged (Fig. 7d). This may indicate that the contact area between the Co-W alloy/MWCNT composite film and the alumina counter surface is smaller than that between the Co-W alloy film and the counter surface. This is likely

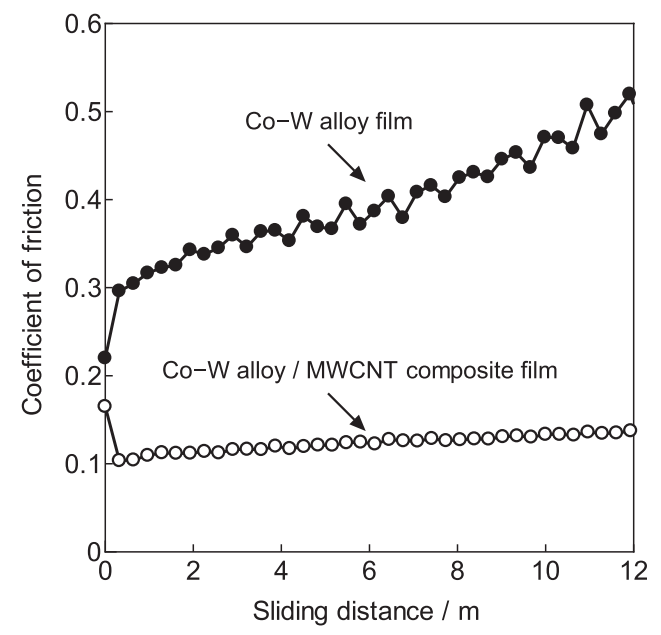

Figure 6. Variation of the coefficient of friction for the Co-W alloy/MWCNT composite film and the $\mathrm{Co}-\mathrm{W}$ alloy film. Test conditions; temperature: room temperature, test load: $2 \mathrm{~N}$, rotation speed: $1.0 \mathrm{~cm} \mathrm{~s}^{-1}$, sliding distance: $12 \mathrm{~m}$. 


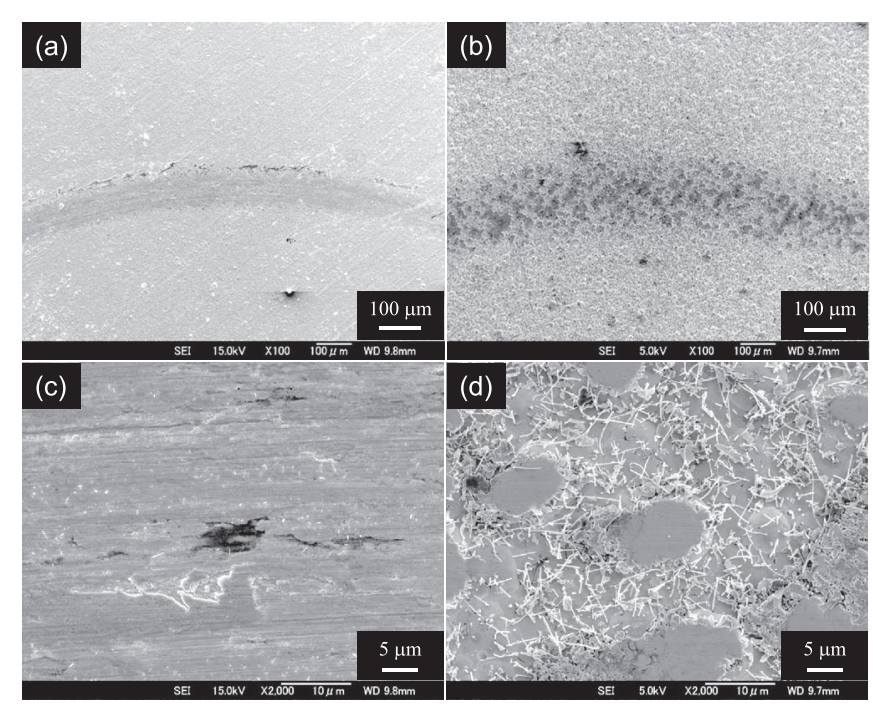

Figure 7. Surface SEM images of wear scars on the films after the wear tests: (a) Co-W alloy film, (b) Co-W alloy/MWCNT composite film, (c) enlarged scar of (a), and (d) enlarged scar of (b). Test conditions; temperature: room temperature, test load: $2 \mathrm{~N}$, rotation speed: $1.0 \mathrm{~cm} \mathrm{~s}^{-1}$, sliding distance: $12 \mathrm{~m}$.

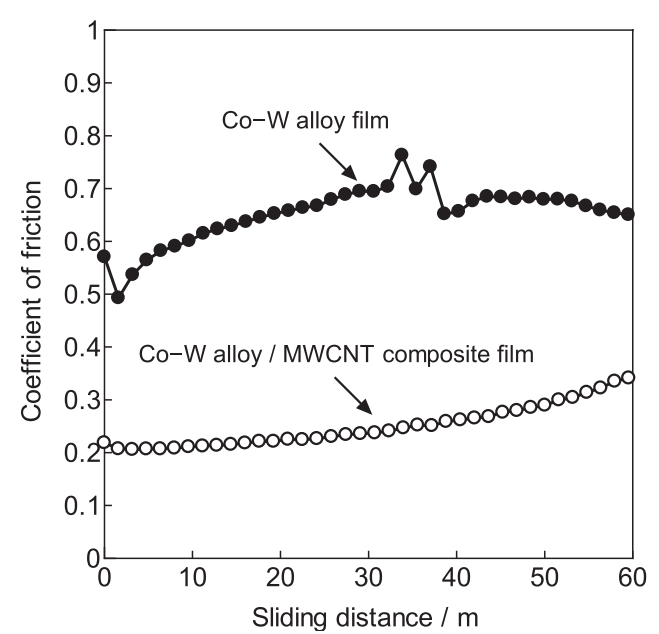

Figure 8. Variation of coefficient of friction for the Co-W alloy/MWCNT composite film and the Co-W alloy film under severe conditions. Test conditions; temperature: room temperature, test load: $5 \mathrm{~N}$, rotation speed: $5.0 \mathrm{~cm}$ $\mathrm{s}^{-1}$, sliding distance: $60 \mathrm{~m}$.
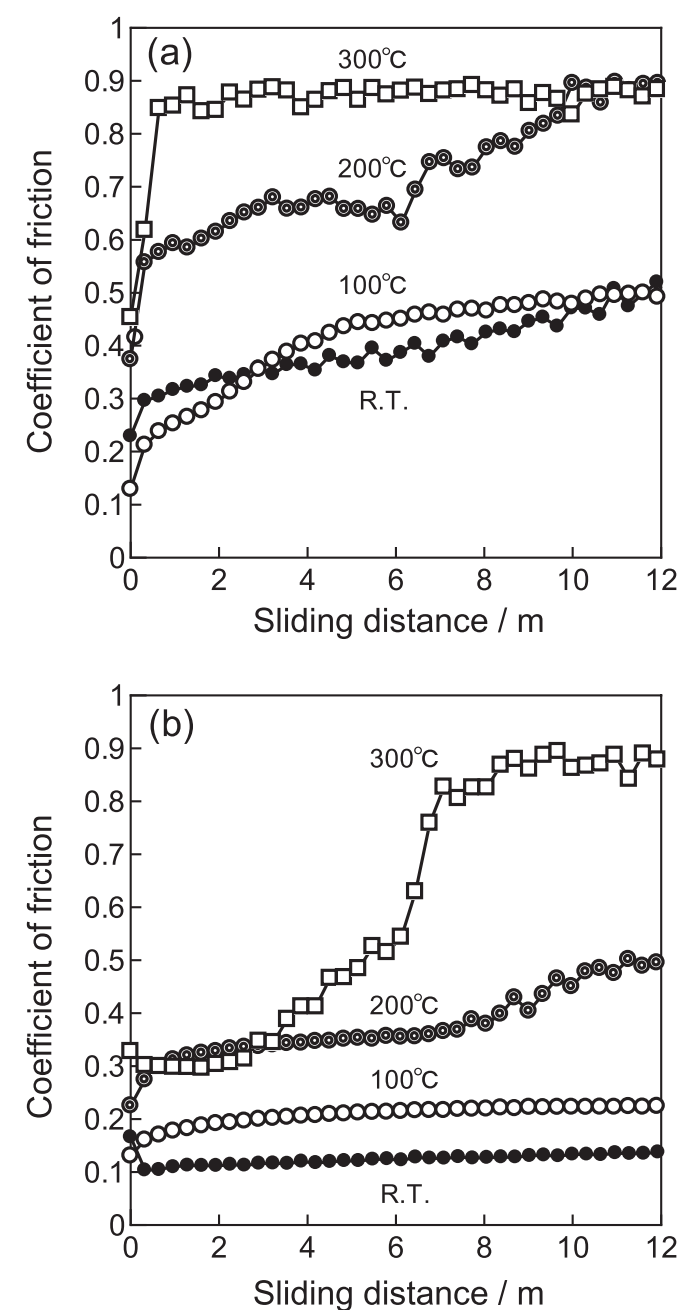

Figure 9. Variation of coefficient of friction for (a) the Co-W alloy/MWCNT composite film and (b) the Co-W alloy film at elevated temperatures. Test conditions; temperature: room temperature $-300^{\circ} \mathrm{C}$, test load: $1 \mathrm{~N}$, rotation speed: $1.0 \mathrm{~cm} \mathrm{~s}^{-1}$, sliding distance: $12 \mathrm{~m}$. 
Table II. Wear rates at various temperatures.

\begin{tabular}{lcc}
$\begin{array}{l}\text { Temperature } \\
\left({ }^{\circ} \mathrm{C}\right)\end{array}$ & $\begin{array}{c}\text { Co-W alloy film } \\
\left(\mathrm{mm}^{3} \mathrm{~N}^{-1} \mathrm{~m}^{-1}\right)\end{array}$ & $\begin{array}{c}\text { Co-W alloy/MWCNT } \\
\text { composite film } \\
\left(\mathrm{mm}^{3} \mathrm{~N}^{-1} \mathrm{~m}^{-1}\right)\end{array}$ \\
\hline R. T. & $*$ & $*$ \\
100 & $*$ & $*$ \\
200 & $0.9 \times 10^{-4}$ & $0.9 \times 10^{-4}$ \\
300 & $2.7 \times 10^{-4}$ & $2.6 \times 10^{-4}$ \\
*Exact evaluation is impossible &
\end{tabular}

due to the very shallow wear scars. The wear rates for the Co-W alloy film and the Co-W alloy/MWCNT composite film tended to increase with increasing temperature. However, the evident difference between the Co-W alloy film and the Co-W alloy/MWCNT composite film was not seen at each temperature. The decrease in hardness of the films at high temperature may be related to this result.

\section{Conclusions}

A Co-W alloy/MWCNT composite film, with uniform distribution of MWCNTs in a homogeneous Co-W alloy matrix, was fabricated using an electrodeposition technique. The Co-W alloy/MWCNT composite film clearly exhibited a lower coefficient of friction than the $\mathrm{Co}-\mathrm{W}$ alloy film at room temperature. Although the coefficient of friction of the Co-W alloy/MWCNT composite film increased with increasing test temperature, the coefficient of friction of the $\mathrm{Co}-\mathrm{W}$ alloy/MWCNT composite film was lower than that of the Co-W alloy film.

\section{References}

1. M. A. M. Ibrahim, S. S. A. E. Rehim, and S. O. Moussa, J. Appl. Electrochem., 33, 627 (2003).

2. S. Belevskii, S. P. Yushchenko, and A. I. Dikusar, Surf. Eng. Appl. Electrochem., 45, 446 (2009).

3. D. P. Weston, P. H. Shipway, S. J. Harris, and M. K. Cheng, Wear, 267, 934 (2009).

4. D. P. Weston, S. J. Harris, H. Capel, N. Ahmed, P. H. Shipway, and J. M. Yellup, Trans. Inst. Met. Finish, 88, 47 (2010).

5. D. P. Weston, S. J. Harris, P. H. Shipway, N. J. Weston, and G. N. Yap, Electrochim. Acta, 55, 5695 (2010).

6. Z. Ghaferi, K. Raeissi, M. A. Golozar, and H. Edris, Surf. Coat. Technol., 206, 497 (2011).
7. M. Mulakutla, V. K. Kommineni, and S. P. Harimkar, Appl. Surf. Sci., 258, 2886 (2012).

8. F. Su and P. Huang, Mater. Chem. Phys., 134, 350 (2012).

9. F. Su, C. S. Liu, and P. Huang, Appl. Surf. Sci., 258, 6550 (2012).

10. F. Su, C. Liu, and P. Huang, J. Alloy. Compd., 557, 228 (2013).

11. P. Bera, H. Seenivasan, K. S. Rajam, C. Shivakumara, and S. K. Parida, Surf. Interface, Anal., 45, 1026 (2013).

12. F. Su, C. Liu, and P. Huang, Wear, 300, 114 (2013).

13. M. L. Holt, Trans. Electrochem. Soc., 71, 301 (1937).

14. M. L. Holt, R. E. Black, and P. F. Hoglund, J. Electrochem. Soc., 84, 353 (1943).

15. W. E. Clark and M. L. Holt, J. Electrochem. Soc., 94, 244 (1948).

16. W. E. Clark and M. H. LieMzke, J. Electrochem. Soc., 99, 245 (1952).

17. T. Omi and H. Yamamoto, J. Electrochem. Soc., 119, 168 (1972).

18. M. Donten, J. Solid State Electrochem., 3, 87 (1999).

19. N. Tsyntsaru, H. Cesiulis, A. Budreika, X. Ye, R. Juskenas, and J. P. Celis, Surf. Coat. Technol., 206, 4262 (2012).

20. W. H. Safranek, The properties of Electrodeposited Metals and Alloys, p. 63, American Elsevier, New York (1974).

21. A. Brenner, Electrodeposition of Alloys, Vol. 2, Academic Press, New York (1963).

22. M. Donten, T. Gromulski, and Z. Stojek, J. Alloy Comp., 279, 272 (1998).

23. S. A. Silkin, S. S. Belevskii, A. S. Grandinar, V. I. Petrenko, I. V. Yakovets, N. I. Tsyntsaru, and A. I. Dikusar, Surf. Eng. Appl. Electrochem., 46, 206 (2010).

24. A. Bodaghi and J. Hosseini, Surf. Eng., 28, 632 (2012).

25. R. A. Mirzoev, O. Mokhkhamad, and E. S. Tolypin, J. Appl. Chem. USSR, 65, 959 (1992).

26. M. Mulukutla, A. Singh, and S. P. Harimkar, Trans. Int. Met. Finish, 90, 316 (2012).

27. N. Periene, L. Orlovskaya, and A. Cesuniene, Bull. Electrochem., 12, 597 (1996).

28. Z. A. Hamid, Mater. Lett., 57, 2558 (2003).

29. S. A. Silkin, S. S. Belevskii, N. I. Tsyntsaru, A. I. Shulman, A. N. Shchuplyakov, and A. I. Dikusar, Surf. Eng. Appl. Electrochem., 45, 1 (2009).

30. S. S. Belevskii, N. I. Tsyntsaru, and A. I. Dikusar, Surf. Eng. Appl. Electrochem., 46, 91 (2010).

31. S. S. Belevskii, A. P. Kosava, S. P. Yushchenko, E. A. Yakhova, A. I. Shulman, and A. I. Dikusar, Surf. Eng. Appl. Electrochem., 47, 4 (2011).

32. M. Svensson, U. Wahlstrom, and G. Holmbon, Surf. Coat. Technol., 105, 218 (1998).

33. A. Oberlin, M. Endo, and T. Koyama, J . Cryst . Growth, 32, 335 (1976).

34. S. Iijima, Nature, 354, 56 (1991).

35. X. H. Chen, J. C. Peng, X. Q. Li, F. M. Deng, J. X. Wang, and W. Z. Li, J. Mater. Sci. Lett., 20, 2057 (2001).

36. S. Arai, A. Fujimori, M. Murai, and M. Endo, Mater. Lett., 62, 3545 (2008)

37. Y. Suzuki, S. Arai, and M. Endo, J. Electrochem. Soc., 157, D50 (2010).

38. W. X. Chen, J. P. Tu, H. Y. Gan, Z. D. Xu, Q. G. Wang, J. Y. Lee, Z. L. Liu, and X. B. Zhang, Surf. Coat. Technol., 160, 68 (2002).

39. X. H. Chen, C. S. Chen, H. N. Xiao, X. B Liu, L. P. Zhou, S. L. Li, and G. Zhang, Tribol. Int., 39, 22 (2006).

40. S. Arai, T. Sato, and M. Endo, J. Electrochem. Soc., 157, D570 (2010).

41. M. Endo, CHEMTECH, American Chemical Society, Sept., 568 (1998).

42. N. Sekine, K. Sekine, and T. Yamashita, Japanese Patent 3985904 (2006).

43. S. Arai and M. Endo, Electrochem. Commun., 5, 797 (2003).

44. S. Arai, M. Endo, and N. Kaneko, Carbon, 42, 641 (2004).

45. S. Arai and M. Endo, Electrochem. Solid-State Lett., 7, C25 (2004).

46. P. L. Dickrell, S. B. Sinnott, D. W. Hahn, N. R. Raravikar, L. S. Schadler, P. M. Ajayan, and W. G. Sawyer, Tribol. Lett. 18, 59 (2005). 